\title{
Single-Task or Dual-Task? Gait Assessment as a Potential Diagnostic Tool for Alzheimer's Dementia
}

\author{
Chorong $\mathrm{Oh}^{*}$ \\ School of Rehabilitation and Communication Sciences, Ohio University, Athens, OH, USA
}

Handling Associate Editor: Manuel Montero-Odasso

Accepted 10 September 2021

Pre-press 8 October 2021

\begin{abstract}
.
Background: A person's gait performance requires the integration of sensorimotor and cognitive systems. Therefore, a person's gait may be influenced by concurrent cognitive load such as simultaneous talking. Although it has been known that gait performance of people with Alzheimer's dementia (AD) is compromised when they attempt a dual-task walking task, it is unclear if using a dual-task gait performance during an $\mathrm{AD}$ assessment yields higher diagnostic accuracy.

Objective: This study was designed to compare the predictive power for $\mathrm{AD}$ of dual-task gait performance in an $\mathrm{AD}$ assessment to that of single-task gait performance.

Methods: Participants (14 with AD and 15 healthy controls) walked across the GAITRite@Portable Walkway mat under three different cognitive load conditions: no simultaneous cognitive load, walking while counting numbers by ones, and walking while completing category naming.

Results: Multiple logistic regression revealed that the gait performance under a dual-task condition (i.e., concurrent counting or category naming) increased the proportion of variance explained by the FAP, SL, and DST, of the incidence of AD.

Conclusion: Dual-task walking and talking may be a more effective diagnostic feature than single-task walking in a comprehensive $\mathrm{AD}$ diagnostic assessment.
\end{abstract}

Keywords: Alzheimer's disease, dementia, diagnosis, dual-task, gait, screening

\section{INTRODUCTION}

It has long been believed that the motor system is separate from the cognitive system both functionally and anatomically. Based on this perception, walking has been considered an over-learned and automatic activity. However, the motor and cognitive systems are interwoven at the cerebrum level [1], thus, gait coordination in walking cannot be completely spontaneous automatic. Rather, it involves continuous

\footnotetext{
${ }^{*}$ Correspondence to: Chorong Oh, School of Rehabilitation and Communication Sciences, Ohio University, 1 Ohio University Dr., Grover Center W235, Athens, OH 45701, USA. Tel.: +1 740593 4719; E-mail: ohc@ohio.edu.
}

control of the body position [2] as well as highermental processes such as attention, working memory, decision-making, and problem-solving [3]. In other words, successful gait performance requires appropriate integration of the sensorimotor and cognitive systems [4]. When a person fails to combine the two systems successfully, the risk of falls may be elevated. Previous studies have shown that a concurrent cognitive load can affect postural control such as gait and result in injurious falls [1, 5-8].

As gait performance requires the coordination of sensorimotor and cognitive systems, gait instability is commonly observed in people with Alzheimer's dementia (AD) [9-14]. The high incidence of gait 
instability among people with dementia has resulted in recommendations for providing fall-prevention training $[15,16]$. In addition, gait compromise in people with $\mathrm{AD}$ may be an early sign of the disease $[9,13$, 17-19]. To date, the majority of studies investigating gait performance in people with $\mathrm{AD}$ have employed a single-task paradigm, which involves walking only. However, dual-task gait assessment such as walking and talking testing can provide more practical insight given that people commonly combine the two activities in their daily lives [14]. This combination creates a commonly occurring dual-task activity that requires both motor control and cognitive performance [20]. The manipulation of the concurrent cognitive load (i.e., talking) affects gait [21] and thus, the gait assessment under different levels of cognitive load (i.e., different speech tasks) may be useful to show the impact of cognitive load on gait. Concurrent walking and talking is more taxing for people with $\mathrm{AD}$ because of their cognitive impairments [14, 20, 21].

Given the relationship between cognitive and walking performances, authors of recent studies have started to employ dual-task walking assessment and have suggested adopting the dual-task paradigm as a screening tool for cognitive impairment. For example, Rosso and colleagues proposed that dual-task walking assessment can be used as a risk assessment tool for mild cognitive impairment (MCI) [22]. Similarly, Mancioppi and colleagues stated that a dualtask assessment incorporating cognitive and motor tasks is effective for MCI diagnosis [23]. Finally, de Oliveira Silva and colleagues suggested that poor dual-task gait performance should be considered as a functional screening tool for dementia [24].

Despite the usefulness of a dual-task walking assessment to screen cognitive impairment, it is still unclear whether the dual-task assessment significantly improves the accuracy in detecting $\mathrm{AD}$, compared to the single-task paradigm. In order to suggest the inclusion of dual-task gait performance in $\mathrm{AD}$ screening/diagnosis tools, it should be clear that the dual-task assessment is more desirable than the single-task assessment. Therefore, this study was designed to investigate the predictive power of gait performance both as a single-task and when gait is paired with a concurrent cognitive load in a dual-task. It is hypothesized that 1) gait performance of people with $\mathrm{AD}$ will deteriorate when completing a dual-task of walking and talking in comparison to the singletask of walking without a cognitive load, showing greater decrements when the dual-task demand is increased, and 2) the addition of a concurrent cog- nitive load will yield a significant improvement in $\mathrm{AD}$ detection.

\section{METHODS}

\section{Participants}

Fourteen individuals with AD and fifteen healthy older adults participated in this study, approved by the institutional review board at Ohio University. The individuals with $\mathrm{AD}$ were those who 1) were diagnosed with probable AD per the NINCDS-ADRDA Work Group procedures [25] but with no additional neurological diagnosis, 2) obtained a score representing mild to moderate dementia (a score between 80 and 129) on the Dementia Rating Scale 2 (DRS2) [26], and 3) had no history of injurious falls within 12 months of participation. The healthy older adults were eligible to participate in this study if they obtained scores in the normal range $(\geq 26)$ using the Montreal Cognitive Assessment (MoCA) [27]. A MoCA score of 26 and higher is considered not pathological [27]. In addition, the healthy participants were required to have no history of injurious falls in the past 12 months.

All participants exhibited sufficient vision and hearing to respond appropriately to the orally delivered study instructions. In addition, they were able to walk $580 \mathrm{~cm}$ with or without assistance. The average age of the people with AD was 78.03 years (standard deviation $[S D]=12.06)$ with an average of 15.81 years $(S D=2.48)$ of education. This group obtained a mean score of $88.14(S D=7.07)$ on the DRS-2. For healthy older adults, the mean age was 72.71 years $(S D=11.86)$ with 15.92 years $(S D=2.08)$ of education. On average, the healthy older adults scored a $27.73(S D=1.29)$ on the MoCA, which was above the cutoff score (26) for possible cognitive impairment. The two groups did not differ significantly in age $(t(25)=1.08, p=0.23)$ or education $(t(25)=0.61$, $p=0.53)$. The participants' demographic information can be found in Table 1.

\section{Instrumentation}

The GAITRite $\odot$ Portable Walkway System from CIR Systems, Inc., was employed to obtain quantified gait performance from each participant. The walkway system consists of an electronic walkway mat and the gait analysis software. The walkway mat is $580 \mathrm{~cm}-$ long and $88 \mathrm{~cm}$-wide and encapsulates 18,432 sensors in an active area $488 \mathrm{~cm}$-long and $61 \mathrm{~cm}$-wide 
Table 1

Demographic information of participants

\begin{tabular}{lcc}
\hline & People with AD & $\begin{array}{c}\text { Neurologically } \\
\text { Healthy Controls }\end{array}$ \\
\hline Number of Participants & 14 (9 Women, 5 Men) & 15 (10 Women, 5 Men $)$ \\
Walking Assistance & 2 walker, 1 cane, & 1 cane \\
Age $(S D)$, y & 1 human assistance & \\
Education $(S D)$, y & $78.03(12.06)$ & $72.71(11.86)$ \\
Duration of disease, y & $15.81(2.48)$ & $15.92(2.08)$ \\
Cognitive Test Sore & $5.11(2.08)$ & Not Applicable \\
$S D$, standard deviation; DRS-2, Dementia Rating Scale-2; MoCA, Montreal Cognitive Assessment.
\end{tabular}

with $1.27 \mathrm{~cm}$ between the sensors. The sensors record 24 temporal and 14 spatial gait parameters from each footfall at a 120 samples per second and a temporal resolution of $18.75 \mathrm{~ms}$. The GAITRite $\odot$ system is allows walkers to be tested using walking aids of their choice. The gait analysis software isolates traces of walking aids that are separate from footfalls and erases them. When signs of walking aids are not identified correctly, they can be manually removed. The GAITRite $\odot$ Portable Walkway System exhibits strong validity and reliability. McDonough and colleagues found excellent intraclass correlation coefficient (ICC) between paper-and-pencil and GAITRite $\bigcirc$-measured spatial parameters $($ ICC $>95$ ) and between video-based and GAITRite $\odot$-measured temporal parameters (ICC > 93) [28]. Bilney and colleagues reported that GAITRite $@$ system had strong validity and test-retest reliability for specific gait parameters when compared to the Clinical Stride Analyzer, a valid and reliable tool for gait assessment (e.g., ICC for velocity, stride length, and cadence between the two systems $=0.99$ ) [29]. Parallel results were found by Webster and colleagues who stated that the GAITRite@ system had excellent validity and reliability for specific gait parameters (e.g., velocity, cadence, step time variables, etc.) in comparison to the Vicon-512, a 3-demensional motion analysis system. (e.g., ICC > 92 and repeatability coefficients between $1.0 \%$ and $5.9 \%$ of mean values for velocity) [30].

\section{Procedures}

This study followed the study protocol used in a previous study [14]. Participants were directed to complete walks on the $980 \mathrm{~cm}$-long GAITRite(C) mat including $200 \mathrm{~cm}$ off either end for acceleration and deceleration under three different cognitive load conditions: the baseline (single-task), low cognitive load (dual-task), and high cognitive load (dual-task) conditions. In the baseline condition, participants were asked to walk along the GAITRite $\odot$ walkway mat normally without talking. The low cognitive load condition was defined as walking while counting numbers by ones. For this task, a two-digit number was randomly selected as a starting number and given to each individual. Lastly, the high cognitive load condition consisted of walking while generating as many words in a given category (e.g., animal) as possible. This task was drawn from the category fluency test by Benton [31].

Prior to completing the three walking conditions, each participant had an opportunity(es) to practice the dual-task conditions while seated and walking to ensure that $\mathrm{s} / \mathrm{he}$ understood the tasks. Participants were instructed to use any kind of walking assistance (e.g., human assistance or a cane) as needed to represent their daily ambulation. All participants were able to complete the dual-task walking. On average, individuals with $\mathrm{AD}$ counted 10 numbers $(S D=1.6)$ and generated 4 words $(S D=2.0)$ while healthy controls counted 12 numbers $(S D=2.1)$ and generated 8 words $(S D=1.3)$ under the cognitive load conditions. Each condition was repeated two times, and the three walking conditions were distributed randomly to account for potential order effects. Breaks were offered to the participants as many times and at any time during the experiment session.

\section{Analyses}

For statistical analyses, four gait parameters were selected as dependent variables: functional ambulation profile (FAP), stride length (SL), velocity, and double support time (DST). The FAP is a composite gait score that ranges from 0 to 100 ; a score between 95 and 100 is typical for healthy adults. First described by Nelson [32], the FAP is widely used to evaluate the stability of gait. Although FAP is an aggregate score considering various gait parameters, 


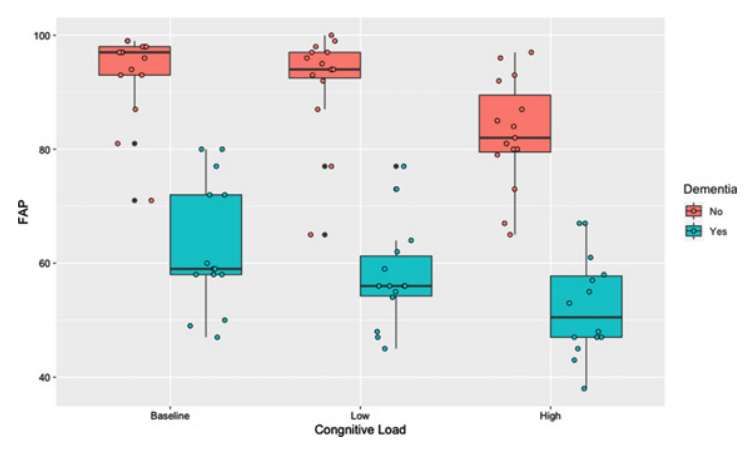

Fig. 1. Functional Ambulation Profile (FAP) by cognitive load.

other important parameters such as SL and DST are not factored into the FAP calculation. In addition, for the FAP computation, a person's gait velocity is normalized after taking the person's leg length into account. Therefore, SL, DST, and the direct measurement of gait velocity were selected for separate analyses.

In order to determine the predictive power of gait performance with three different task settings (baseline, low cognitive load, and high cognitive load) to the incidence of $\mathrm{AD}$, multiple logistic regression analyses were conducted with the incidence of $\mathrm{AD}$ as the dependent variable (Responses: Yes/No), and one of the four selected gait parameters combined with single- or dual-task conditions as the independent variables (e.g., FAP under the baseline condition, FAP under the low cognitive load condition, and FAP under the high cognitive load condition, etc.). Furthermore, to examine whether the gait performance under the dual-task conditions can account for greater variance in the incidence of $\mathrm{AD}$, the performance at the baseline, low and high cognitive load conditions was entered sequentially for each gait parameter, resulting in several different models. This was followed by a model comparison based on residual deviation with the model with only single-task performance as the reference. These analyses were conducted for each of the four gait parameters separately. The analyses were conducted using $R$ version 3.6.3.

\section{RESULTS}

\section{Functional ambulation profile}

All models of the Omnibus test for multiple logistic regression indicated that FAP both under the singleand dual-task conditions accounted for a significant amount of variability between the two groups of participants (Table 2). Furthermore, Table 2 shows a $15 \%$ proportional improvement in pseudo $\mathrm{R}^{2}$ from model 1 (reference model) to model 4 (full model). Thus, the predictive power increased significantly when the FAP score under the high cognitive load condition was added to the reference model with or without the score under the low cognitive load condition. Similarly, Table 3 shows a model comparison analysis based on residual deviance. Specifically, model 3 utilizing the FAP scores under the baseline and high cognitive load conditions $(p=0.001)$ and the model 4 using the FAP scores under all of the three conditions ( $p=0.004)$ were significantly better than the reference model, in which only FAP under the baseline condition was included, or the model 2 where the FAP scores under the baseline and low cognitive load conditions were taken into account. The results are also illustrated in Fig. 1.

\section{Velocity}

Figure 2 shows that both groups walked slower when taxed with a higher cognitive load. On average, people with $\mathrm{AD}$ walked at a rate of $48.47 \mathrm{~cm} / \mathrm{s}$ $(S D=17.35)$ under the baseline condition, $42.76 \mathrm{~cm} / \mathrm{s}$

Table 3

Model Comparison of Functional Ambulation Profile $($ ref. $=$ model 1$)$

\begin{tabular}{lccc}
\hline Model & $\begin{array}{c}\text { Residual } \\
\text { Deviance }\end{array}$ & AIC & $p$ \\
\hline 1 & 10.71 & 14.71 & - \\
2 & 8.93 & 14.93 & 0.1815 \\
3 & 0.00 & 6 & $0.001064^{* *}$ \\
4 & 0.00 & 8 & $0.004716^{* *}$ \\
${ }^{* *} p<0.01$. & & &
\end{tabular}

Table 2

Omnibus Test of Functional Ambulation Profile (FAP)

\begin{tabular}{lccccc}
\hline Model & IVs & $\begin{array}{c}\text { McFadden } \\
\text { Adjusted R }\end{array}$ & $\begin{array}{c}\text { Cox \& } \\
\text { Snell R }\end{array}$ & Nagel R & $p$ \\
\hline 1 & FAP1 & 0.63 & 0.64 & 0.85 & $<0.0001$ \\
2 & FAP1 + FAP2 & 0.63 & 0.66 & 0.88 & $<0.0001$ \\
3 & FAP1 + FAP3 & 0.85 & 0.75 & 1 & $<0.0001$ \\
4 & FAP1 + FAP2 + FAP3 & 0.80 & 0.75 & 1 & $<0.0001$ \\
\hline
\end{tabular}




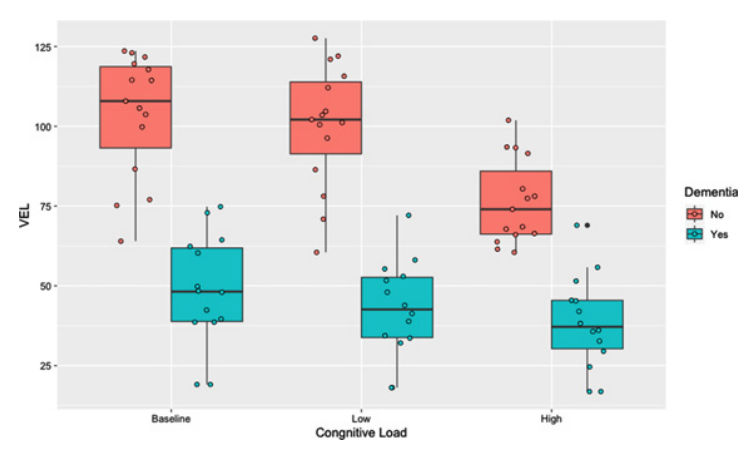

Fig. 2. Velocity by cognitive load.

$(S D=15.11)$ under the low cognitive load condition, and $38.54 \mathrm{~cm} / \mathrm{s}(S D=13.26)$ under the high cognitive load condition. Similarly, healthy older adults' walking velocity was $103.63 \mathrm{~cm} / \mathrm{s}(S D=19.28)$ under the baseline condition which decreased slightly to 100.17 $(S D=19.24)$ under the low cognitive load condition and to $76.31 \mathrm{~cm} / \mathrm{s}(S D=13.26)$ under the high cognitive load condition.

Similar to FAP, both single- and dual-task velocity explained significant amount of variability in predicting AD (for all models, $p<0.001$, see Table 4 ). Although adding the dual-task velocity improved the model fit, the improvement was not statistically significant as detailed in Table 5.

\section{Stride length}

In accordance with FAP and velocity, participants' SL decreased for cognitive load (see Fig. 3). People with AD walked with a mean SL of $84.26 \mathrm{~cm}$ $(S D=24.66)$ under the baseline condition, which was shortened to a mean of $76.85 \mathrm{~cm}(S D=23.65)$ under the low cognitive load condition, then to $68.53 \mathrm{~cm}$ $(S D=14.99)$ under the high cognitive load condition. The healthy controls' SL was more persistent across cognitive load conditions than the AD group's as the baseline condition SL was $119.26 \mathrm{~cm}(S D=16.01)$, which decreased to $118.54 \mathrm{~cm}(S D=15.92)$ and to $112.25 \mathrm{~cm}(S D=10.10)$ under low and high cognitive load conditions respectively.
The logistic regression analysis showed that the single-task SL alone did not predict the AD status of the participant, but any combination of single- and dual-task SL did (i.e., Models 2 and 4, $p<0.001$; Model 3, $p=0.001$, as in Table 6). Similarly, when compared to the reference model, the single-task SL combined with the SL under low cognitive load $(p<0.01)$, with the SL under high cognitive load $(p<0.001)$, or with the SL under both low and high cognitive load $(p<0.001)$ conditions significantly improved the model fit (Table 7).

\section{Double support time}

Given the nature of this parameter, participants' DST was in an inverse pattern to the other three parameters. Namely, DST of both people with AD and healthy older adults increased with higher cognitive load. People with AD needed a mean DST of $0.950 \mathrm{~s}(S D=0.784)$ to complete walking along the $580 \mathrm{~cm}$ walkway mat under the baseline condi-

Table 5

Model Comparison of Velocity (ref. = model 1)

\begin{tabular}{lccc}
\hline Model & $\begin{array}{c}\text { Residual } \\
\text { Deviance }\end{array}$ & AIC & $p$ \\
\hline 1 & 9.67 & 13.67 & - \\
2 & 7.40 & 13.40 & 0.1319 \\
3 & 7.62 & 13.62 & 0.1525 \\
4 & 7.31 & 15.31 & 0.3078 \\
\hline
\end{tabular}

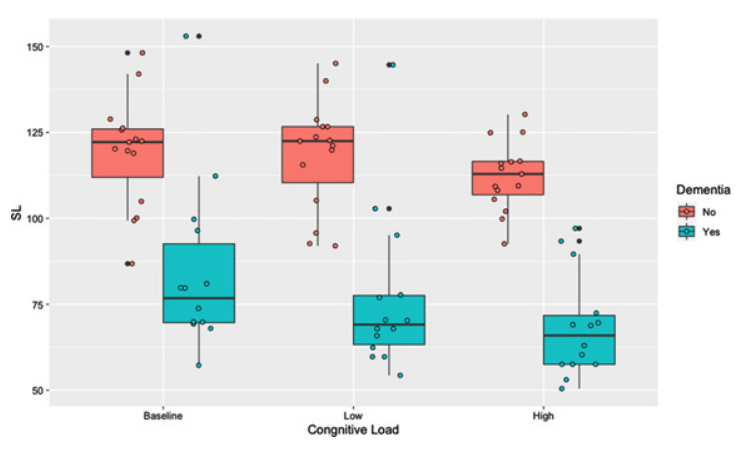

Fig. 3. Stride length by cognitive load.

Table 4

Omnibus Test of Velocity (VEL)

\begin{tabular}{lccccc}
\hline Model & IVs & $\begin{array}{c}\text { McFadden } \\
\text { Adjusted } \mathrm{R}^{2}\end{array}$ & $\begin{array}{c}\text { Cox \& } \\
\text { Snell } \mathrm{R}^{2}\end{array}$ & Nagel $\mathrm{R}^{2}$ & $p$ \\
\hline 1 & VEL1 & 0.66 & 0.65 & 0.87 & $<0.0001$ \\
2 & VEL1 + VEL2 & 0.67 & 0.68 & 0.90 & $<0.0001$ \\
3 & VEL1 + VEL3 & 0.66 & 0.67 & 0.90 & $<0.0001$ \\
4 & VEL1 + VEL2 + VEL3 & 0.62 & 0.68 & 0.90 & $<0.0001$ \\
\hline
\end{tabular}


Table 6

Omnibus Test of Stride Length (SL)

\begin{tabular}{lccccc}
\hline Model & IVs & $\begin{array}{c}\text { McFadden } \\
\text { Adjusted } \mathrm{R}^{2}\end{array}$ & $\begin{array}{c}\text { Cox \& } \\
\text { Snell R }^{2}\end{array}$ & Nagel R & $p$ \\
\hline 1 & SL1 & 0.28 & 0.41 & 0.54 & 0.123 \\
2 & SL1 + SL2 & 0.41 & 0.54 & 0.72 & $<0.0001$ \\
3 & SL1 + SL3 & 0.85 & 0.75 & 1 & 0.001 \\
4 & SL1 + SL2 + SL3 & 0.80 & 0.75 & 1 & $<0.0001$ \\
\hline
\end{tabular}

Table 7

Model Comparison of Stride Length (ref. = model 1)

\begin{tabular}{lccc}
\hline Model & $\begin{array}{c}\text { Residual } \\
\text { Deviance }\end{array}$ & AIC & $p$ \\
\hline 1 & 37.79 & 29.13 & - \\
2 & 17.59 & 23.59 & $0.006046^{* *}$ \\
3 & $<0.000$ & 6 & $<0.0001^{* * *}$ \\
4 & $<0.000$ & 8 & $<0.0001^{* * *}$ \\
${ }^{* *} p<0.01{ }^{* * * *} p<0.001$. & &
\end{tabular}

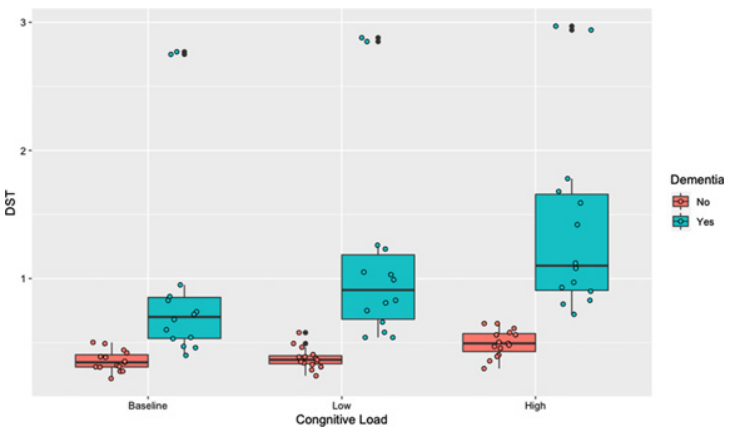

Fig. 4. Double support time by cognitive load.

tion. The mean DST increased to $1.143 \mathrm{~s}(S D=0.767)$ under the low cognitive load condition and to $1.409 \mathrm{~s}$ $(S D=0.738)$ under the high cognitive load condition. The healthy older adults walked with an average DST of $0.357 \mathrm{~s}(S D=0.081)$ under the baseline condition and $0.377 \mathrm{~s}(S D=0.084)$ under the low cognitive load condition. The DST for the healthy older adults increased to $0.497 \mathrm{~s}(S D=0.106)$ under the high cognitive load condition (see Fig. 4). Similar to FAP and velocity, significant improvements in identifying people with $\mathrm{AD}$ occurred for both single- and dual-task DSTs (all $p<0.001$, see Table 8 ). The model compar-
Table 9

Model Comparison of Double Support Time $($ ref. $=$ model 1)

\begin{tabular}{lccc}
\hline Model & $\begin{array}{c}\text { Residual } \\
\text { Deviance }\end{array}$ & AIC & $p$ \\
\hline 1 & 14.10 & 18.18 & - \\
2 & 6.10 & 12.10 & $0.004486^{* * *}$ \\
3 & $<0.000$ & 6 & $0.0001663^{* * *}$ \\
4 & $<0.000$ & 8 & $0.0008343^{* * *}$ \\
${ }^{* *} p<0.01 ;{ }^{* * *} p<0.001$. & &
\end{tabular}

ison revealed that adding one or both of the dual-task DST to the reference model significantly improved the model fit (Table 9). More specifically, adding DST under low cognitive load condition to the baseline model yielded a significant improvement $(p<0.01)$, so did adding DST at under the high cognitive load condition $(p<0.001)$, and adding both $(p<0.001)$.

\section{DISCUSSION}

The present investigation was designed to demonstrate the usefulness of adopting the dual-task gait assessment as a component for $\mathrm{AD}$ diagnosis. Two hypotheses were developed in alignment with the purpose: First, gait performance of people with $\mathrm{AD}$ will be compromised when they are cognitively taxed, and second, the dual-task gait assessment will improve the accuracy for screening AD than the single-task gait assessment. The findings of the current study fully confirmed the first hypothesis and partially the second hypothesis.

It was evident that concurrent cognitive load affected gait in people with AD: all of the four gait parameters (i.e., FAP, velocity, SL, and DST) were compromised as cognitive demands increased.

Table 8

Omnibus Test of Double Support Time (DST)

\begin{tabular}{lccccc}
\hline Model & IVs & $\begin{array}{c}\text { McFadden } \\
\text { Adjusted R }\end{array}$ & $\begin{array}{c}\text { Cox \& } \\
\text { Snell R }\end{array}$ & Nagel R & $p$ \\
\hline 1 & DST1 & 0.55 & 0.59 & 0.79 & $<0.0001$ \\
2 & DST1 + DST2 & 0.70 & 0.69 & 0.92 & $<0.0001$ \\
3 & DST1 + DST3 & 0.85 & 0.75 & 1 & $<0.0001$ \\
4 & DST1 + DST2 + DST3 & 0.80 & 0.75 & 1 & $<0.0001$ \\
\hline
\end{tabular}


As Kahneman proposed, the simultaneous activity of walking and talking requires cognitive resource allocation [33], specifically executive function and attention divided between gait and cognition [34-39]. The ability to share the cognitive resource is particularly impaired in people with AD [40-42]. Neuroimaging studies have shown that brain networks are shared by cognitive and motor control in the frontal and temporal areas, which results in poorer gait performance such as slow gait (velocity) [21, 43-45]. Due to the increased load on cortical activity for complicated situations when gait stability is affected, people with dementia have difficulty allocating sufficient cognitive resources available in the frontal or temporal lobes [44]. These situations may result in a higher risk and prevalence of injurious falls among people with $\mathrm{AD}$ [3]. This claim reinforces studies showing poorer gait performance associated with damage/atrophy in the prefrontal and hippocampal regions [45-48]. More specifically, these authors found that reduced walking speeds share neural substrate such as smaller hippocampus [48-51]; accumulation of amyloid- $\beta$ [51]; hyperintensities in the subcortical regions [52]; and stride length variability with Apolipoprotein E4 [53, 54]. In sum, the dual-task gait assessment has shown its effectiveness as a potential dementia diagnostic tool [14, 55-57].

In the present study adoption of a dual task in gait assessment appeared to be more useful for AD screening than a single task of walking without a concurrent cognitive load. In general, the addition of the concurrent cognitive load improved the probability of detecting AD significantly. Three of the four selected gait parameters (i.e., FAP, SL, and DST) explained a larger proportion of the variance and had higher odds ratios under the high cognitive load condition of simultaneous walking and category naming. For DST, factoring in counting numbers by ones also improved the model fit. However, for velocity neither the low nor high cognitive load increased the probability of detecting AD. It should be noted that people with AD in this study slowed their gait when cognitively taxed. This finding is consistent with findings of previous studies showing slow gait speed in people with $\mathrm{AD}$ or other dementias when performing a dual-task activity [20, 21, 36, 37, 58]. This current investigation revealed that including the dual-task gait velocity, either under the low or high cognitive load condition, did not significantly improve the model fit over the single-task gait velocity. This non-significant effect of adding the dual-task gait velocity on predicting incidence of AD may be attributed to the small sample size or the experimental tasks (i.e., counting numbers and category naming) that do not represent daily living activity. Alternatively, the short walkway mat might have not been adequate to induce effects of high cognitive load on walking, as people often recall category members well in the beginning but struggle after they name several [59]. As an option, future studies may consider weighing various gait parameters differently for a more accurate AD screening/diagnosis. To date, there has been no study investigating how to weigh different gait parameters as a component of an $\mathrm{AD}$ diagnosis. However, when Meilán et al. [60] weighed different speech parameters to discriminate $\mathrm{AD}$, they reported $84.8 \%$ accuracy. Therefore, scrutinizing impacts of different gait parameters on $\mathrm{AD}$ screening/diagnosis may yield a more accurate result.

Several limitations exist in this study: First, the small sample size (total $n=29$ ) makes this study underpowered for the logistic regression analyses and the specific subpopulation recruited for this study (i.e., people with mild to moderate AD with limited consideration of functional differences) reduces the generalizability of the current results. The insufficient power may lead to a reduced reproducibility of the findings or may even result in yielding unstable and/or null findings. Therefore, future studies including more participants from more diverse populations are warranted. In fact, a number of studies have proposed that poorer gait performance may be associated with non-Alzheimer's type dementia [5, 61, 62]. Future studies that are sufficiently powered for logistic regression analyses will provide stronger evidence to support the findings of previous studies. In addition, studies that consider functional differences in people with different levels of cognitive functioning will be useful. Second, participants of this study were instructed to use any kind of walking aids that they typically used for their daily ambulation. When a participant needed human assistance, the requested assistance was provided to the degree that does not impede or benefit the person's walking performance. Although wheeled-walker may increase walking speed, [e.g., 63, 64], stride length [64] and swing time [64], the increase in walking speed is not significant when a person walks with a cane or crutch [63]. The limited data on the effects of walking aids on parameters of gait make it difficult to draw a generalized conclusion. Thus, future dual-task studies should include samples of people who use a variety of walking aids, including human assistance. Third, walking along the short walkway mat while count- 
ing numbers or completing a naming task may not be sufficient to represent daily walking performance. Thus, it is recommended that future investigations adopt more real-life dual-task activities such as spontaneous conversation and consider assisted walking and independent walking groups separately. Finally, investigations of gait parameters other than the four selected ones for this investigation may add valuable information for determining the optimum gait measurements to adopt for dual-task assessments for people with dementia.

Despite the limitations, the current investigation adds theoretical and empirical evidence to the literature emphasizing the role of dual-task gait assessments in an AD assessment battery. The current results indicate the challenges experienced by people with AD whose cognitive reserve is less available when walking and completing a simultaneous oral task. These data indicate that the dual-task gait assessment may supplement the current AD screening/diagnostic tools.

\section{ACKNOWLEDGMENTS}

I gratefully acknowledge the contribution of Dr. Elizabeth Madden for providing partial data. I also would like to thank Dr. Richard Morris and Xianhui Wang for their careful readings of the manuscript and statistical advice.

Authors' disclosures available online (https:// www.j-alz.com/manuscript-disclosures/21-0690r2).

\section{REFERENCES}

[1] Hausdorff JM, Schweiger A, Herman T, Yogev-Seligmann G, Giladi N (2008) Dual-task decrements in gait: Contributing factors among healthy older adults. J Gerontol A Biol Sci Med Sci 63, 1335-1343.

[2] Bruijn SM, van Dieën JH (2018) Control of human gait stability through foot placement. $J R$ Soc Interface 15, 20170816.

[3] Sheridan PL, Hausdorff JM (2007) The role of higher-level cognitive function in gait: Executive dysfunction contributes to fall risk in Alzheimer's disease. Dement Geriatr Cogn Disord 24, 125-137.

[4] Lee NG, Kang TW, Park HJ (2020) Relationship between balance, gait, and activities of daily living in older adults with dementia. Geriatr Orthop Surg Rehabil 11, 2151459320929578.

[5] Regnaux JP, David D, Daniel O, Smail DB, Combeaud M, Bussel B (2005) Evidence for cognitive processes for involved in the control of steady state walking in healthy subjects and after cerebral damage. Neurorehabil Neural Repair 19, 125-132.

[6] LaPointe LL, Stierwalt JAG, Maitland CG (2010) Talking while walking: Cognitive loading and injurious falls in Parkinson's disease. Int J Speech Lang Pathol 12, 455-459.

[7] Rochester L, Galna B, Lord S, Burn D (2014) The nature of dual-task interference during gait in Parkinson's disease. Neurosci 265, 83-94.

[8] Oh C, Lapointe LL (2017) Changes in cognitive load and effects on parameters of gait. Cogent Psychol 4, 1372872.

[9] Verghese J, Lipton RB, Hall CB, Kuslansky G, Katz MJ, Buschke B (2002) Abnormality of gait as a predictor of non-Alzheimer's dementia. New Engl J Med 347, 1761-1768.

[10] Allan LM, Ballad CG, Burn DJ, Kenny RA (2005) Prevalence and safety of gait disorders in Alzheimer's and non-Alzheimer's disease. J Am Geriatr Soc 53, 1681-1687.

[11] Beauchet O, Allali G, Berrut G, Hommet C, Dubost V, Assal F (2008) Gait analysis in demented subjects: Interests and perspectives. Neuropsychiatr Dis Treat 4, 155-160.

[12] Silverberg NB (2011) Assessment of cognition in early dementia. Alzheimers Dement 7, e60-e70.

[13] Gras LZ, Kanaan SF, McDowd JM, Colgrove YM, Burns J, Pohl PS (2015) Balance and gait of adults with very mild Alzheimer disease. J Geriatr Phys Ther 38, 1-7.

[14] Oh C, Morris, RJ, Lapointe LL, Stierwalt JAG (2021) Spatial-temporal parameters of gait associated with Alzheimer disease: A longitudinal analysis. J Geriatr Psychiatry Neurol 34, 46-59.

[15] van Doorn C, Gruber-Baldini AL, Zimmerman S, Hebel JR, Port CL, Baumgarten M, Quinn CC, Taler G, May C, Magaziner J; Epidemiology of Dementia in Nursing Homes Research Group (2003) Dementia as a risk factor for falls and fall injuries among nursing home residents. J Am Geriatr Soc 51, 1213-1218.

[16] Kossee NM, de Groot MH, Vuillerman N, Hortobágyi T, Lamoth CJC (2015) Factors related to the high fall rate in long-term care residents with dementia. Int Psychogeriatr 27, 803-814.

[17] Scarmeas N, Albert M, Brandt J, Blacker D, Hadjigeorgiou G, Papadimitriou A, Dubois B, Sarazin M, Wegesin D, Marder K, Bell K, Honig L, Stern Y (2005) Motor signs predict poor outcomes in Alzheimer disease. Neurology 64, 1696-1703.

[18] Bruce-Keller AJ, Brouillette RM, Tudor-Locke C, Foil HC, Gahan WP, Correa J, Nye DM, Keller JN (2012) Assessment of cognition, physical performance, and gait in the context of mild cognitive impairment and dementia. $J$ Am Geriatr Soc 60, 176-177.

[19] Savica R, Wennberg AM, Hagen C, Edwards K, Roberts RO, Hollman JH, Knopman DS, Boeve BF, Machulda MM, Petersen RC, Mielke MM (2017) Comparison of gait parameters for predicting cognitive decline: The Mayo Clinic study of aging. J Alzheimers Dis 55, 559-567.

[20] Montero-Odasso MM, Sarquis-Adamson Y, Speechley M, Borrie MJ, Hachinski VC, Wells J, Riccio PM, Schapira M, Sejdic E, Camicioli RM, Bartha R, McIlroy WE, MuirHunter S (2017) Association of dual-task gait with incident dementia in mild cognitive impairment: Results from the gait and brain study. JAMA Neurol 74, 857-865.

[21] Muir SW, Speechley M, Wells J, Borrie M, Gopaul K, Montero-Odasso M (2012) Gait assessment in mild cognitive impairment and Alzheimer's disease: The effect of dual-task challenges across the cognitive spectrum. Gait Post 35, 96-100.

[22] Rosso AL, Metti AL, Faulkner K, Redfern M, Yaffe K, Launer L, Elizabeth Shaaban C, Nadkarni NK, Rosano C (2019) Complex walking tasks and risk for cognitive decline 
in high functioning older adults. J Alzheimers Dis 71, S65-S73.

[23] Mancioppi G, Fiorini L, Rovini E, Zeghari R, Gros A, Manera V, Robert P, Cavallo F (2021) Innovative motor and cognitive dual-task approaches combining upper and lower limbs may improve dementia early detection. Sci Rep 11, 7449.

[24] de Oliveira Silva F, Ferreira JV, Plácido J, Deslandes AC (2020) Spatial navigation and dual-task performance in patients with dementia that present partial dependence in instrumental activity of daily living. IBRO Rep 9, 52-57.

[25] McKhann G, Drachman D, Folstein M (1984) Clinical diagnosis of Alzheimer's disease: Report of the NINCDS-ADRDA work group under the auspices of department of health and human services task force on Alzheimer's disease. Neurology 34, 939-944.

[26] Jurica PJ, Leitten CL, Mattis S (2001) Dementia Rating Scale-2. Psychological Assessment Resources, Odessa, FL.

[27] Nasreddine ZS, Phillips NA, Bédirian V, Charbonneau $\mathrm{S}$, Whitehead V, Collin I, Cummings JL, Chertkow $\mathrm{H}$ (2005) The Montreal Cognitive Assessment, MoCA: A brief screening tool for mild cognitive impairment. J Am Geriatr Soc 53, 695-699.

[28] McDough AL, Batavia M, Chen FC, Kwon S, Ziai J (2001) The validity and reliability of the GAITRite system's measurements: A preliminary evaluation. Arch Phys Med Rehabil 82, 419-425.

[29] Bilney B, Morris M, Webster K (2003) Concurrent related validity of the GAITRite walkway system for quantification of the spatial and temporal parameters of gait. Gait Post 17, 68-74.

[30] Webster KE, Wittwer JE, Feller JA (2005) Validity of the GAITRite walkway system for the measurement of averaged and individual step parameters of gait. Gait Post 22, 317-321.

[31] Benton AL (1968) Differential behavioral effects in frontal lobe disease. Neuropsychologia 6, 53-60.

[32] Nelson AJ (1974) Functional ambulation profile. Phy Ther 54, 1059-1065.

[33] Kahneman D (1973) Attention and effort. Prentice-Hall INC, Englewood Cliffs, NJ.

[34] Yogev-Seligmann G, Hausdorff JM, Giladi N (2008) The role of executive function and attention in gait. Mov Disord 23, 329-472.

[35] Watson NL, Rosano C, Boudreau RM, Simonsick EM, Ferrucci L, Sutton-Tyrrell K, Hardy SE, Atkinson HH, Yaffe K, Satterfield S, Harris TB, Newman AB; Health ABC Study (2010) Executive function, memory, and gait speed decline in well-functioning older adults. J Gerontol A Biol Sci Med Sci 65, 1093-1100.

[36] IJmker T, Lamoth CJC (2012) Gait and cognition: The relationship between gait stability and variability with executive function in persons with and without dementia. Gait Post 35, 126-130.

[37] MacAulay RK, Wagner MT, Szeles D, Milano NJ (2017) Improving sensitivity to detect mild cognitive impairment: Cognitive load dual-task gait speed assessment. J Int Neuropsychol Soc 23, 493-501.

[38] Taylor ME, Lasschuit DA, Lord SR, Delbaere K, Kurrle SE, Mikolaizak AS, Kvelde T, Close JCT (2017) Slow gait speed is associated with executive function decline in older people with mild to moderate dementia: A one year longitudinal study. Arch Gerontol Geriatr 73, 148-153.

[39] Montero-Odasso M, Almeida QJ, Bherer L, Burhan AM, Camicioli R, Doyon J, Fraser S, Muir-Hunter S, Li KZH,
Liu-Ambrose T, McIlroy W, Middleton L, Morais JA, Sakurai R, Speechley M, Vasudev A, Beauchet O, Hausdorff JM, Rosano C, Studenski S, Verghese J; Canadian Gait and Cognition Network (2019) Consensus on shared measures of mobility and cognition: From the Canadian Consortium on Neurodegeneration in Aging (CCNA). J Gerontol A Biol Sci Med Sci 74, 897-909.

[40] Perry RJ, Hodges JR (1999) Attention and executive deficits in Alzheimer's disease. A critical review. Brain 122, 383-404.

[41] Baddeley AD (2001) Attentional control in Alzheimer's disease. Brain 124, 1492-1508.

[42] Sheridan PL, Solomont JS, Kowall N, Hausdorff JM (2003) Influence of executive function on locomotor function: Divided attention increases gait variability in Alzheimer's disease. J Am Geriatr Soc 51, 1633-1637.

[43] Annweiler C, Beauchet O, Bartha R, Montero-Odasso M (2012) Slow gait in MCI is associated with ventricular enlargement: Results from the Gait and Brain Study. J Neural Transm 120, 1083-1092.

[44] Jamour M, Becker C, Synofzik M, Maetzler W (2012) Gait changes as an early indicator of dementia. Z Gerontol Geriatr 45, 40-44.

[45] Rosso AL, Studenski SA, Chen WG, Aizenstein HJ, Alexander NB, Bennett DA, Black SE, Camicioli R, Carlson MC, Ferrucci L, Guralnik JM, Hausdorff JM, Kaye J, Launer LJ, Lipsitz LA, Verghese J, Rosano C (2013) Aging, the central nervous system, and mobility. J Gerontol A Biol Sci Med Sci 68, 1379-1386.

[46] Annweiler C, Beauchet O, Celle S, Roche F, Annweiler T, Allali G, Bartha R, Montero-Odasso M; WALK Team (Working group Angers-London for Knowledge) (2012) Contribution of brain imaging to the understanding of gait disorders in Alzheimer's disease: A systematic review. Am J Alzheimers Dis Other Demen 27, 371-380.

[47] Montero-Odasso M, Hachinski V (2013) Preludes to brain failure: Executive dysfunction and gait disturbances. Neurol Sci 35, 601-604.

[48] Rosso AL, Verghese J, Metti AL, Boudreau RM, Aizenstein HJ, Kritchevsky S, Harris T, Yaffe K, Satterfield S, Studenski S, Rosano C (2017) Slowing gait and risk for cognitive impairment: The hippocampus as a shared neural substrate. Neurology 89, 336-342.

[49] Beauchet O, Launay CP, Annweiler C, Allali G (2015) Hippocampal volume, early cognitive decline, and gait variability: Which association? Exp Gerontol 61, 98-104.

[50] Sakurai R, Bartha R, Montero-Odasso M (2019) Entorhinal cortex volume is associated with dual-task gait cost among older adults with MCI: Results from the Gait and Brain Study. J Gerontol A Biol Sci Med Sci 74, 698-704.

[51] Del Campo N, Payoux P, Djilali A, Delrieu J, Hoogendijk EO, Rolland Y, Cesari M, Weiner MW, Andrieu S, Vellas B; MAPT/DSA Study Group (2016) Relationship of regional brain $\beta$-amyloid to gait speed. Neurology 86, 36-43.

[52] Nadkarni NK, McIlroy WE, Mawji E, Black SE (2009) Gait and subcortical hyperintensities in mild Alzheimer's disease and aging. Dement Geriatr Cogn Disord 28, 295-301.

[53] Macaulay R, Allaire T, Brouillette R, Foil H, Bruce-Keller A, Keller JN (2016) Apolipoprotein E genotype linked to spatial gait characteristics: Predictors of cognitive dual task gait change. PLoS One 11, e0156732.

[54] Sakurai R, Montero-Oddaso M (2017) Apolipoprotein E4 allele and gait performance in mild cognitive impairment: Results from the gait and brain Study 2017. J Gerontol A Biol Sci Med Sci 72, 1676-1682. 
[55] Studenski S, Perera S, Wallace D, Chandler JM, Duncan PW, Rooney E, Fox M, Guralnik JM (2003) Physical performance measures in the clinical setting. J Am Geriatr Soc 51, 314-322.

[56] Studenski S, Perera S, Patel K, Rosano C, Faulkner K, Inzitari M, Brachm J, Chandler J, Cawthon P, Connor, EB, Nevitt M, Visser M, Kritchevsky S, Badineli S, Harris T, Newman AB, Caulet J, Ferrucci L, Guralink J (2011) Gait speed and survival in older adults. JAMA 305, 50-58.

[57] Montero-Odasso M, Schapira M, Duque G, Soriano ER, Kaplan R, Camera LA (2005) Gait disorders are associated with non-cardiovascular falls in elderly people: A preliminary study. BMC Geriatrics $\mathbf{1}, 15$.

[58] Cullen S, Borrie M, Carroll S, Sarquis-Adamson Y, Pieruccini-Faria F, McKay S, Montero-Odasso M (2019) Are cognitive subtypes associated with dual-task gait performance in a clinical setting? J Alzheimers Dis 71, S57-S64.

[59] Luo L, Luk G, Bialystok E (2010) Effect of language proficiency and executive control on verbal fluency performance in bilinguals. Cognition 114, 29-41.
[60] Meilán JJ, Martínez-Sánchez F, Carro J, López DE, MillianMorell L, Arana JM (2014) Speech in Alzheimer's disease: Can temporal and acoustic parameters discriminate dementia? Dement Geriatr Cogn Disord 37, 327-334.

[61] Verghese J, Wang C, Lipton RB, Holtzer R, Xue X (2007) Quantitative gait dysfunction and risk of cognitive decline and dementia. J Neurol Neurosurg Psychiatry 78, 929-935.

[62] Ceide ME, Ayers EI, Lipton R, Verghese J (2018) Walking while talking and risk of incident dementia. Am J Geriatr Psychiatry 26, 580-588.

[63] Härdi I, Bridenbaugh SA, Gschwind YJ, Kressig RW (2014) The effect of three different types of walking aids on spatio-temporal gait parameters in community-dwelling older adults. Aging Clin Exp Res 26, 221-228.

[64] Schülein S, Barth J, Rampp A, Rupprecht R, Eskofier BM, Winkler J, Gaßmann KG, Klucken J (2017) Instrumented gait analysis: A measure of gait improvement by a wheeled walker in hospitalized geriatric patients. J Neuroeng Rehabil $\mathbf{1 4}, 18$. 